\title{
Objective pulsatile tinnitus associated with internal carotid artery loop formation: A case report
}

\author{
Internal karotis arter loop oluşumu ile ilişkili objektif pulsatil tinnitus: Olgu sunumu
}

Alper Yenigün, Ömer Faruk Çalım, Seda Sezen Göktaş, Erol Şentürk

Department of Otolaryngology, Medical Faculty of Bezmialem Vakuf University, İstanbul, Turkey

\begin{abstract}
Tinnitus is common in the general population while pulsatile tinnitus is rare; however, it is often a diagnosable and treatable otological symptom. Tinnitus may be subjective or objective. The etiology of pulsatile tinnitus may be turbulence in blood flow, vascular stenosis or increasing blood flow rate. Tinnitus is divided into two sections: the arterial one, which is synchronized with the heartbeat and the venous hum, which is synchronized with respiration. A 55-year-old female patient was admitted with symptoms of forgetfulness and tinnitus in the left ear, which was synchronized with heartbeat and was gradually increased in the last two years. In this article, we report the loop formation in the same side internal carotid artery of a 55-year-old patient who was presented with a onesided objective pulsatile tinnitus.
\end{abstract}

Keywords: Internal carotid artery; magnetic resonance angiography; objective pulsatile tinnitus.

Tinnitus is a very common otological symptom affecting $30 \%$ of the global population. ${ }^{[1]}$ It can be divided in two subgroups: pulsatile and non-pulsatile. ${ }^{[1]}$ If pulsatile tinnitus is synchronized with the heartbeat, it is presumed arterial in origin and if synchronized with respiration, it is presumed venous in origin. ${ }^{[1]}$ Most forms of pulsatile tinnitus are synchronized with the heartbeat and accompanied by arterial pulsations. Arterial pulsations are most probably delivered to the cochlea through cerebrospinal fluid. ${ }^{[2]}$ The etiology of almost all arterial pulsatile tinnitus cases that are synchronized with the heartbeat and are mostly vascular in origin (except intracranial hypertension)

\begin{abstract}
$\ddot{O} Z$
Tinnitus genel nüfusta sıklıkla görülürken, pulsatil tinnitus daha nadir görülmekle birlikte sıklıkla tanı konulabilen ve tedavi edilebilen otolojik bir semptomdur. Tinnitus subjektif veya objektif olabilir. Pulsatil tinnitus etyolojisinde kan akımında oluşan türbülans, vasküler darlık veya artan kan akım hızı olabilir. Tinnitus iki bölüme ayrılır: kalp atışı ile senkronize olan arteriyel ve solunum ile senkronize olan venöz uğultu. Elli beş yaşında kadın hasta sol kulağında kalp atışıyla senkronize olan ve son iki yıldır giderek artan tinnitus ve unutkanlık şikayetiyle başvurdu. Bu

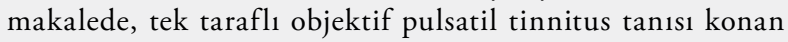
55 yaşındaki bir hastanın aynı taraflı internal karotis arterdeki loop formasyonu sunuldu.
\end{abstract}

Anahtar sözcükler: İnternal karotis arter; manyetik rezonans anjiyografi; objektif pulsatil tinnitus.

can be identified through magnetic resonance imaging (MRI) and magnetic resonance angiography (MRA). ${ }^{[1]}$ Although the incidence of loop formation in the internal carotid artery (ICA) is approximately $10-16 \%$ among the general population, its clinical significance is still not clear. ${ }^{[3]}$ This paper presents a case of objective pulsatile tinnitus on the same side of loop formation in the ICA.

\section{CASE REPORT}

A 55-year-old female patient presented with symptoms of forgetfulness and tinnitus in the left ear, which was synchronized with her heartbeat and gradually increased 
in the last two years. She had no otalgia, otorrhea, aural fullness, or hearing loss. She denied any history of head and neck surgery, trauma, infectious diseases, or smoking. Her otorhinolaryngological examination did not indicate any abnormalities. On auscultation with a stethoscope over the preauricular, parietal scalp, mastoid and neck areas, pulsations were heard, synchronous with the heartbeat. Pure tone audiometric findings were in the normal range, with speech discrimination scores of $100 \%$ for both ears. Temporal bone CT was reported as normal. Since she had symptoms of forgetfulness, she was evaluated in consultation with the neurosurgery department and a cervical MR angiogram was requested, revealing loop formation of the left ICA (Figure 1). Surgery and medical treatment were not given to the patients. The patient is currently on outpatient follow-up. Written informed consent was obtained from the patient for publication.

\section{DISCUSSION}

Pulsatile tinnitus may be subjective or objective. The etiology of pulsatile tinnitus may be turbulence in blood flow, vascular stenosis or increasing blood flow rate. ${ }^{[4]}$ We think that the loop formation in the left ICA might have resulted in turbulent blood flow, causing subjective pulsatile tinnitus synchronous with the heartbeat in this case.

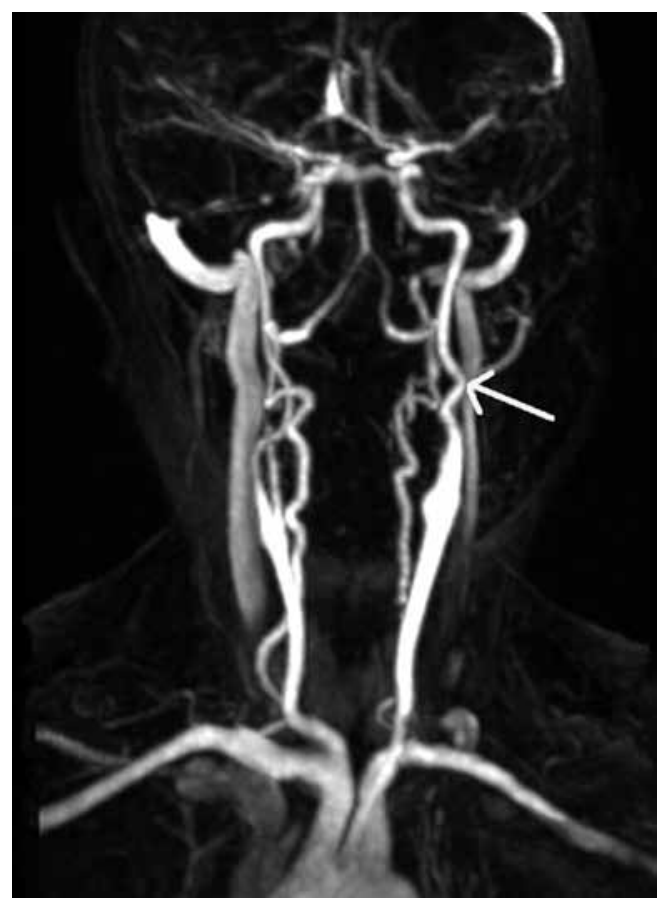

Figure 1. Loop formation of the internal carotid artery demonstrated on cervical magnetic resonance angiogram (arrow).
Several studies demonstrated that pulsatile tinnitus could be secondary to vascular or non-vascular reasons. Sismanis ${ }^{[1]}$ reported that intracranial hypertension was responsible for $45 \%$ of all pulsatile tinnitus. Mattox and Hudgins ${ }^{[5]}$ indicated that dural arteriovenous malformation (DAVM) was the best-known reason for pulsatile tinnitus synchronous with the arterial pulse. Abnormal connections between arterial and venous systems may be congenital or acquired. Post-traumatic pulsatile tinnitus may develop as a result of carotid dissection, AV fistula or carotico-cavernous fistula. Pulsatile tinnitus was observed on the same side in 16-27\% of carotid dissections. ${ }^{[6]}$ Also, pulsatile tinnitus was observed in $5 \%$ of non-traumatic vertebral artery dissections. ${ }^{[7]}$

Carotid dissections consist of the triad of head and neck pain, Horner's syndrome and pulsatile tinnitus. ${ }^{[8]}$ Post-traumatic AV fistulas generally result in pulsatile tinnitus. The most frequently observed post-traumatic fistula is the carotid-cavernous fistula. Furthermore, AVMs of the outer ear, hypoglossal canal and parotid gland also may result in pulsatile tinnitus.

Carotid stenosis is the most common reason for arterial pulsatile tinnitus. ${ }^{[1]}$ The most frequent reasons for it include atherosclerotic disease and fibromuscular dysplasia. Arterial pulsatile tinnitus may not only be caused by the internal carotid artery, but also by stenotic subclavian, external carotid artery, and aberrant occipital artery as well. As seen in the predominant flow occurring in both carotid arteries with basilar artery atresia, the hyperdynamic flow in the ICA may cause pulsatile tinnitus. ${ }^{[9]}$ Anemia, thyrotoxicosis or pregnancy may also cause hyperdynamic flow. ${ }^{[10]}$ Normally, the carotid pulsations are not heard due to the dampening effect of the pericarotidal venous plexus. ${ }^{[9]}$ The development of extensive pneumatization around the carotid artery reduces this dampening effect, increasing the perception of arterial pulsations. ${ }^{[10]}$ This case was observed to have objective pulsatile tinnitus synchronous with the heartbeat on the left since the loop formation in the left internal carotid resulted in turbulent blood flow, reducing the dampening effect of the peri-carotidal venous plexus.

Pulsatile tinnitus is divided into two: arterial, synchronized with the heart beat and venous, synchronized with respiration. Although several vascular reasons have been reported as reasons for pulsatile tinnitus, the development of loop formation in the ICA was shown for the first time as a reason in this paper based on a review of the English literature. Loop formation in the ICA is a subject that merits investigation in different studies in terms of its clinical significance. 


\section{Declaration of conflicting interests}

The authors declared no conflicts of interest with respect to the authorship and/or publication of this article.

\section{Funding}

The authors received no financial support for the research and/or authorship of this article.

\section{REFERENCES}

1. Sismanis A. Pulsatile tinnitus: contemporary assessment and management. Curr Opin Otolaryngol Head Neck Surg 2011;19:348-57.

2. Sohmer H, Freeman S. Further evidence for a fluid pathway during bone conduction auditory stimulation. Hear Res 2004;193:105-10.

3. Nayak BS. Unusual looping of the internal carotid artery in relation to an enlarged lymph node. IJAV 2010;3:84-5.
4. Kim S, Byun J, Park M, Lee S. Pulsatile tinnitus with a dural arterio-venous fistula diagnosed by computed tomography-angiography. Korean J Audiol 2013;17:133-7.

5. Mattox DE, Hudgins P. Algorithm for evaluation of pulsatile tinnitus. Acta Otolaryngol 2008;128:427-31.

6. Baumgartner RW, Bogousslavsky J. Clinical manifestations of carotid dissection. Front Neurol Neurosci 2005;20:70-6.

7. Arnold M, Bousser MG, Fahrni G, Fischer U, Georgiadis D, Gandjour J, et al. Vertebral artery dissection: presenting findings and predictors of outcome. Stroke 2006;37:2499-503.

8. Selim M, Caplan LR. Carotid Artery Dissection. Curr Treat Options Cardiovasc Med 2004;6:249-253.

9. De Ridder D, De Ridder L, Nowé V, Thierens H, Van de Heyning P, Møller A. Pulsatile tinnitus and the intrameatal vascular loop: why do we not hear our carotids? Neurosurgery 2005;57:1213-7.

10. Topal O, Erbek SS, Erbek S, Ozluoglu LN. Subjective pulsatile tinnitus associated with extensive pneumatization of temporal bone. Eur Arch Otorhinolaryngol 2008;265:123-5. 